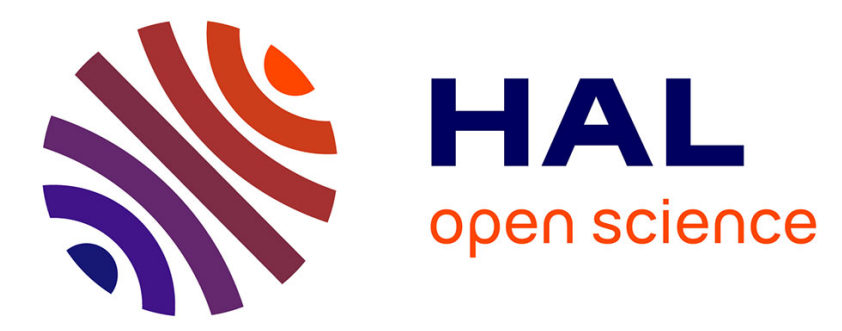

\title{
Devenir des nanoparticules utilisées comme médicament dans l'organisme
}

\author{
Frédéric Lagarce
}

\section{To cite this version:}

Frédéric Lagarce. Devenir des nanoparticules utilisées comme médicament dans l'organisme. Techniques de l'Ingenieur, 2014, pp.MED5050. hal-03179478

\section{HAL Id: hal-03179478 \\ https://univ-angers.hal.science/hal-03179478}

Submitted on 24 Mar 2021

HAL is a multi-disciplinary open access archive for the deposit and dissemination of scientific research documents, whether they are published or not. The documents may come from teaching and research institutions in France or abroad, or from public or private research centers.
L'archive ouverte pluridisciplinaire HAL, est destinée au dépôt et à la diffusion de documents scientifiques de niveau recherche, publiés ou non, émanant des établissements d'enseignement et de recherche français ou étrangers, des laboratoires publics ou privés. 


\section{med5050}

\section{Devenir des nanoparticules utilisées comme médicament dans l'organisme}

\section{Date de publication : 10/10/2014 \\ Par :}

Frédéric LAGARCE

Professeur de biopharmacie, Faculté de pharmacie, Inserm, U 1066 MINT, LUNAM Université, Angers, France

Cet article fait partie de la base documentaire :

Nanotechnologies pour l'énergie, la santé et l'agroalimentaire

Dans le pack : Nanotechnologies

et dans l'univers : Innovations

Document délivré le : 01/12/2014

Pour le compte : 7200097598 - editions ti // nc AUTEURS // 217.109.84.129

Pour toute question :

Service Relation clientèle - Techniques de l'Ingénieur 249 rue de Crimée - 75019 - Paris

par mail infos.clients@teching.com ou au téléphone 0033 (0) 153352020 


\title{
Devenir des nanoparticules utilisées comme médicament dans l'organisme
}

\author{
par Frédéric LAGARCE \\ Professeur de biopharmacie \\ Faculté de pharmacie \\ Inserm, U 1066 MINT, LUNAM Université, Angers, France
}

1. Univers des nanomédecines

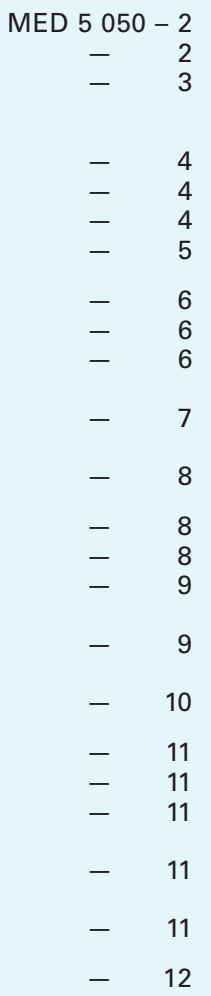

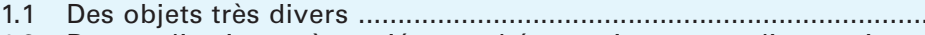

1.2 Des applications très variées en thérapeutique et en diagnostic.....

2. Devenir des nanomédecines après administration

intraveineuse

2.1 Pharmacocinétique des nanoparticules

2.2 Furtivité des nanoparticules.....

2.3 Ciblage actif et ciblage passif, effet de rétention et de perméation.

3. Devenir après administration orale

3.1 Rappels de physiologie pour la voie orale....

3.2 Processus d'absorption des nanomédecines

3.3 Evaluation des performances des nanomédecines pour la voie orale

3.4 Principales applications des nanomédecines utilisées par voie orale.....

4. Devenir après administration cutanée

4.1 Rappel de physiologie de la peau

4.2 Mécanismes de passage des nanoparticules au travers de

Evaluation des perforn sur la peau.

4.4 Applications de I'utilisation des nanomédecines appliquées sur la peau.

5. Devenir après administration pulmonaire

5.1 Rappels physiologiques du poumon

5.2 Devenir des nanomédecines dans le poumon Principaux modèles d'évaluation des nanomédecines utilisées par voie pulmonaire

5.4 Applications de l'utilisation des nanomédecines administrées par voie pulmonaire.

6. Conclusion

es médicaments utilisés aujourd'hui en santé humaine comportent une acti-

vité pharmacologique principale, mais aussi des effets secondaires dits indésirables. Améliorer les performances du médicament en limitant ses potentiels effets toxiques revient à augmenter sa balance bénéfices/risques. Les nanotechnologies apportent des moyens d'augmenter la balance bénéfices/risques en changeant le devenir du médicament dans l'organisme. Ceci revêt un caractère très important dans le domaine des traitements anticancéreux, où l'on recherche un ciblage très fin sur les cellules tumorales et non sur les cellules saines. L'idée sous-tendue par cette stratégie thérapeutique consiste à associer la molécule active avec un vecteur qui possède des propriétés physico-chimiques (taille, charges électrostatiques de surface, hydrophilie, etc.) qui détermineront ses lieux de diffusion dans I'organisme et son élimination. Ainsi, le devenir de la molécule active, médicament, dans l'organisme, ne dépendra plus de ses propriétés chimiques propres mais de celles du vecteur. Ce concept est 
appelé vectorisation. Une vectorisation réussie consiste ainsi à améliorer le ciblage des molécules vers les tissus de l'organisme où l'on désire qu'elles soit actives tout en limitant leur diffusion vers les tissus pour lesquels elles pourrait être toxiques, ceci en allongeant sa durée de résidence dans les tissus d'intérêt pour prolonger l'effet pharmacologique et obtenir des médicaments plus efficaces. La mise au point d'un vecteur efficace et peu toxique repose sur la maîtrise des procédés de fabrication et de caractérisation, parfois difficiles à l'échelle nanométrique, mais aussi sur la connaissance des structures physiologiques, histologiques, biologiques et biochimiques des tissus de l'organisme. En effet, le devenir dans l'organisme du vecteur que l'on désire contrôler, pour maîtriser de fait l'action du médicament, dépendra de l'interaction entre le vecteur et le milieu vivant. Ainsi, en fonction de la voie d'administration du médicament, le vecteur sera en contact avec différents tissus et son trajet dans l'organisme pourra être différent. La discipline qui permet d'étudier le comportement d'un médicament en fonction des structures biologiques qu'il rencontre s'appelle la biopharmacie. Cet article a pour objectif de décrire les concepts particuliers de biopharmacie lorsqu'ils sont appliqués aux vecteurs de médicaments, appelés aussi nanomédecines. Une analyse du devenir des nanomédecines par voie d'administration sera proposée dans cet article afin d'éclairer le formulateur sur les structures cellulaires et tissulaires à prendre en compte pour un design rationnel et efficace des nanomédicaments.

\section{Glossaire}

\begin{tabular}{|c|c|}
\hline Balance bénéfice/risque ; benefit to risk ratio & $\begin{array}{l}\text { Rapport entre les effets bénéfiques et les effets toxiques } \\
\text { (ou secondaires, ou encore indésirables) d'un médicament. }\end{array}$ \\
\hline Transcytose ; trancytosis & $\begin{array}{l}\text { Phénomène de transport d'une molécule au travers d'une cellule avec absorption à un pôle } \\
\text { de la cellule et sécrétion au pôle opposé. }\end{array}$ \\
\hline Phagocytose ; phagocytosis & $\begin{array}{l}\text { Phénomène de captation de molécules dans l'organisme par des cellules spécialisées (les } \\
\text { macrophages) qui induiront ensuite l'élimination de ces molécules. Ce phénomène } \\
\text { concourt à la détoxification de l'organisme. }\end{array}$ \\
\hline $\begin{array}{l}\text { Indice de polydispersité ; } \\
\text { polydispersity index }\end{array}$ & $\begin{array}{l}\text { Indice permettant d'évaluer la dispersité de taille d'une population particulaire. Cet indice } \\
\text { est donné par calcul par les logiciels de granulométrie. Plus cet indice est faible, proche de } \\
0 \text {, plus la population de particules est de taille resserrée et monodisperse. On considère } \\
\text { souvent qu'un indice inférieur à } 0,2 \text { signe une population homogène et monodisperse de } \\
\text { répartition proche d'une gaussienne. }\end{array}$ \\
\hline Screening & $\begin{array}{l}\text { Les techniques de " screening " ou de criblages visent à trier parmi une grande quantité de } \\
\text { candidats médicaments ceux qui pourront avoir un intérêt. Ce sont des techniques rapides } \\
\text { et simples qui permettent de hauts rendements. Les cultures cellulaires constituent un des } \\
\text { outils de screening les plus utilisés. }\end{array}$ \\
\hline Encapsulation & $\begin{array}{l}\text { Action d'associer une molécule active du point de vue pharmaceutique au sein d'un vecteur } \\
\text { tel qu'une nanoparticule ou bien une microparticule. }\end{array}$ \\
\hline
\end{tabular}

\section{Univers des nanomédecines}

\subsection{Des objets très divers}

Dans leur volonté de contrôler le devenir d'une molécule médicament dans l'organisme, que nous appellerons le principe actif dans la suite de ce document, les chercheurs ont développé de multiples solutions technologiques faisant appel au monde nanométrique. Un dossier des Techniques de I'Ingénieur [NM 4 010], spécifiquement dédié à l'étude des nanotechnologies utilisées pour la thérapeutique et le diagnostic, montre la grande diversité des solutions envisagées pour piloter le transport d'un principe actif dans nos tissus jusqu'à sa cible pharmacologique. II est ainsi possible de formuler des nanoparticules à l'aide de polymères biodégradables ou non. Ces nanoparticules peuvent être des systèmes matriciels, on parle alors de nanosphères, ou former une coque entourant un cœur de nature différente (souvent une cavité aqueuse ou huileuse), on parle alors de nanocapsules. II existe de multiples façons de produire des nanoparticules polymères en utilisant par exemple des techniques de nanoémulsification, de nanoprécipitation ou de condensation [NM 4 010]. À côté des nanoparticules polymères, il est possible de trouver des nanosphères lipidiques [1], le plus souvent solides à température ambiante ou des nanocapsules lipidiques qui sont de véritables objets biomimétiques ayant une structure proche des lipoprotéines de notre organisme [2]. Ces nanocapsules lipidiques sont particulièrement intéressantes car 


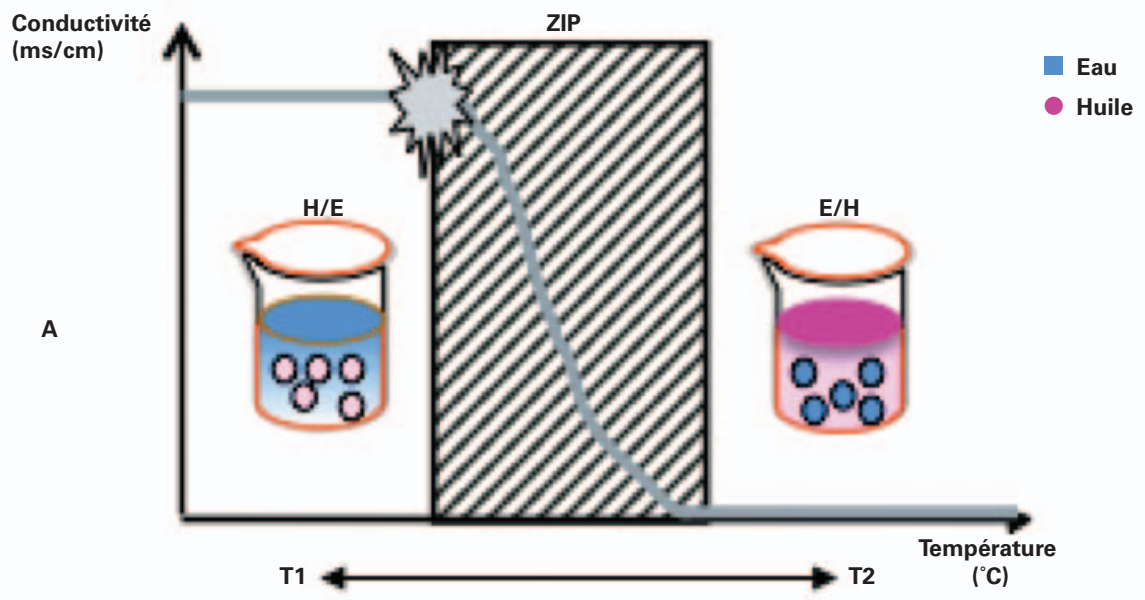

B

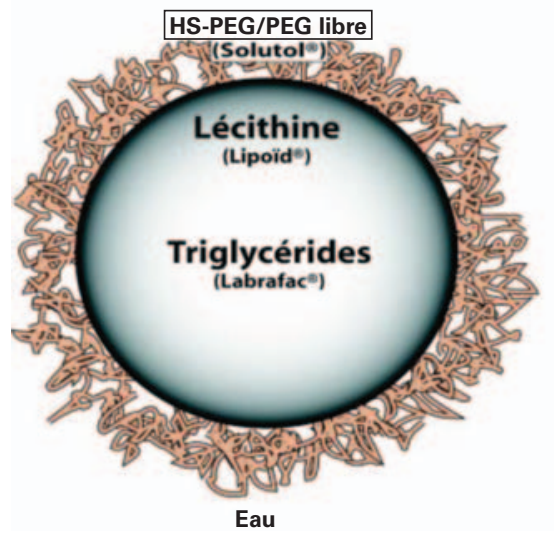

Figure 1 - A - Schéma de production des nanocapsules lipidiques. ZIP : zone d'inversion de phase E/H et H/E : émulsion eau/huile et huile/eau. Le sens de l'émulsion change avec la température et passe par une zone de microémulsion (au niveau de la ZIP), la dilution du système rapide dans I'eau au passage de la ZIP permet de former instantanément les nanocapsules. B - Schéma d'une nanocapsule lipidique composée d'un cœur lipophile fait de triglycérides et d'une coque composée de lécithines et de surfactant (hydroxystéarate de polyethylène glycol)

elles sont produites sans solvant organique (ce qui limite leur toxicité potentielle), à partir de composés sans organismes génétiquement modifiés [3] et sont adaptées à la production à une grande échelle [4]. Leur fabrication est simple et réalisable à basse énergie (figure 1). Le monde des nanoparticules est vaste et s'étend à des structures telles que les liposomes, qui sont des vésicules nanométriques (30 à plus de $900 \mathrm{~nm}$ ) dont la coque est faite d'une ou plusieurs bicouches de phospholipides. On trouve aussi des micelles, qui sont des arrangements supramoléculaires de molécules tensioactives associant les molécules de principe actif, des polymères sur lesquels on a greffé une ou plusieurs molécules de principe actif, ou même des nanoparticules minérales comme les nanoparticules d'or qui peuvent transporter elles aussi des principes actifs.

\subsection{Des applications très variées en thérapeutique et en diagnostic}

Les applications des nanomédecines sont très variées, même si le domaine des traitements anticancéreux constitue l'immense majorité des applications. En effet dans ce domaine thérapeutique le ciblage des cellules cancéreuses à l'aide de vecteurs de médicaments revêt un intérêt tout particulier. II existe des milliers de publications référencées sur les bases de données scientifiques sur ce domaine de recherche et de nombreux ouvrages dédiés à ce sujet. II existe aussi des applications dans d'autres domaines thérapeutiques comme l'infectiologie ou les maladies inflammatoires. De nombreuses applications viennent aussi du fait que l'on cherche à utiliser les nanotechnologies dans le cadre de la thérapie génique en remplacement des vecteurs viraux qui restent potentiellement dangereux. Ainsi, les nanoparticules, en apportant de I'ADN ou des ARN aux cellules, permettent de modifier le phénotype cellulaire en altérant, par exemple, l'expression de protéines délétaires (ceci peut être obtenu par l'interférence ARN) ou au contraire en stimulant la production de protéines d'intérêt (par transfection d'ADN). La thérapie génique est beaucoup utilisée dans le domaine du cancer. Des essais cliniques impliquant des vecteurs non viraux sont aujourd'hui en cours (en 2014) et sont très prometteurs.

En dehors des aspects thérapeutiques, les nanoparticules sont utilisées depuis plus de 25 ans en imagerie médicale. C'est par exemple le cas des nanoparticules d'oxyde de fer utilisées depuis 1989 comme agent de contraste. Les applications en imagerie sont de plus en plus importantes et peuvent inclure aujourd'hui une 
composante thérapeutique. Les nano-objets ont alors un double rôle : imager une lésion et la traiter. Cette nouvelle stratégie s'appelle la théranostique [5].

De ce qui précède, il est aisé de constater que le monde des nanomédecines est vaste tant sur les nano-objets utilisés que sur les applications médicales. Le comportement de ces nouvelles formulations dans l'organisme dépendra de leurs caractéristiques physico-chimiques mais aussi des tissus qu'ils rencontreront en fonction de la voie par laquelle ils sont administrés. Bien comprendre les facteurs jouant sur le devenir de ces nano-objets dans l'organisme est essentiel pour en optimiser les performances.

\section{Devenir des nanomédecines après administration intraveineuse}

\subsection{Pharmacocinétique des nanoparticules}

Après administration sanguine, les nanoparticules vont circuler dans le torrent circulatoire. Pour atteindre les tissus, il faudra que ces transporteurs passent dans les artères puis les artérioles de plus petits diamètres. Ainsi, une dose de nanoparticules administrée dans une veine rejoindra le cœur par la veine cave puis passera obligatoirement dans les poumons pour revenir au cœur par la veine pulmonaire et rejoindre la circulation artérielle par l'artère aorte (figure 2). Le passage par les poumons n'est pas un problème pour ces objets de petite taille, il l'est pour des particules de plus de 5 micromètres de diamètre car le risque d'embolie des petits vaisseaux pulmonaires est alors à prendre en compte. Après passage dans le réseau artériel, si les nanoparticules n'ont pas été captées par les tissus, elles vont être piégées dans les macrophages du système réticulo-endothélial, en particulier dans le foie et dans la rate. À ce titre, les cellules de Küpfer du foie, qui sont des macrophages particuliers, sont la principale source de captation des nanoparticules, du fait de leur grand nombre ( $25 \%$ des cellules hépatiques, $90 \%$ des macrophages de l'organisme) et de leur emplacement en bordure des sinus hépatiques. La rate constitue aussi un moyen très efficace de séquestrer les nanoparticules et donc de limiter leur action thérapeutique. Les débits sanguins artériels de la rate et du foie sont respectivement de $77 \mathrm{ml} / \mathrm{min}$ et de $300 \mathrm{ml} / \mathrm{min}$ [6]. Ainsi, plus les nanoparticules évitent la rétention dans le foie, plus ils vont pouvoir atteindre la rate. Les nanoparticules de taille supérieure à $200 \mathrm{~nm}$ qui sont rigides ou qui ont des formes non sphériques ont plus de chance d'être captées par la rate. Cette rétention splénique, en plus de limiter la biodisponibilité des principes actifs encapsulés dans les nanoparticules, favorise les réactions immunitaires à l'origine du phénomène d'élimination accélérée des nanoparticules lorsqu'une seconde dose est administrée. Ce phénomène a été observé avec des nanoparticules polymères, des liposomes ou des complexes lipidiques [7].

L'élimination des nanoparticules peut être biliaire ou rénale. Les nanoparticules peuvent être excrétées dans la bile par transcytose au sein de vésicules. Ce mécanisme d'élimination a été observé pour des particules non biodégradables de plus de $6 \mathrm{~nm}$ de diamètre hydrodynamique [7]. Les nanoparticules sont aussi éliminées par le rein après filtration glomérulaire le plus souvent après dégradation, on considère en effet que le diamètre maximal de filtration de nanoparticules non modifiées est de 5 à $10 \mathrm{~nm}$, ce qui concerne somme toute peu d'applications. Les quantum dots ou certain nanotubes de carbone de faible diamètre peuvent toutefois être filtrés inchangés par le rein. Certaines nanoparticules à surface hydrophile peuvent repasser dans le sang après réabsorption tubulaire.

\subsection{Furtivité des nanoparticules}

De ce qui précède, on observe que les possibilités d'élimination des nanoparticules de l'organisme sont nombreuses. Or, si I'on veut avoir une partie importante de la dose thérapeutique active sur la cible pharmacologique, il convient de modifier les nanoparticules pour ralentir leur élimination par les macrophages. Cette propriété d'évitement du système immunitaire de reconnaissance de l'organisme est appelée furtivité.

La reconnaissance par le système immunitaire, qui conduira à terme à la phagocytose des nanoparticules, est liée à une étape

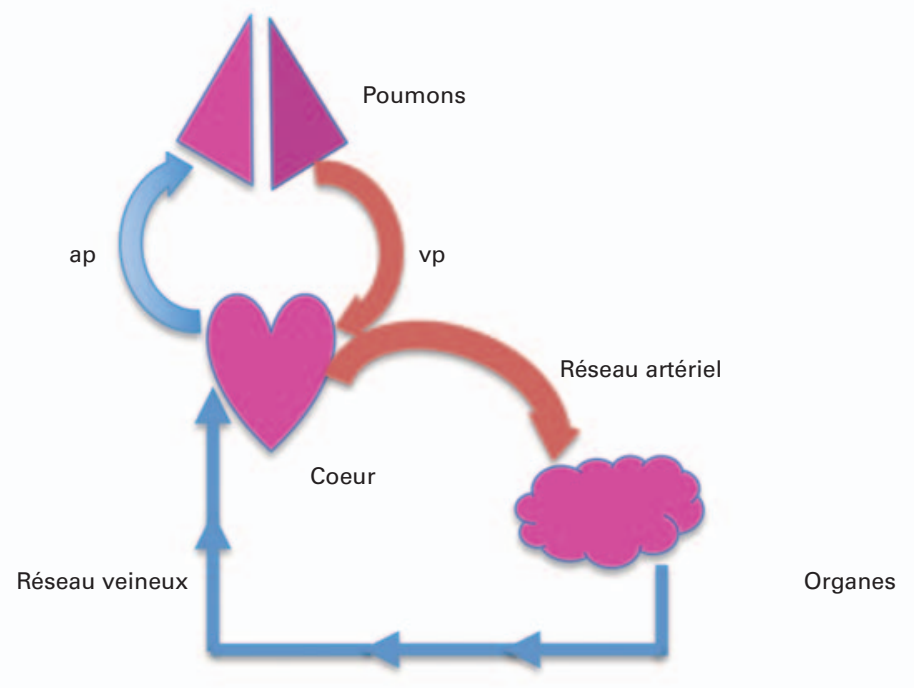

Figure 2 - Schéma de principe de la circulation sanguine. Artère pulmonaire (ap), veine pulmonaire (vp). Le réseau artériel principal commence avec l'artère aorte. Le réseau veineux principal se jette dans le cœur par la veine cave inférieure 


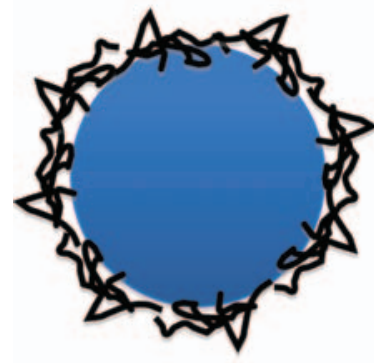

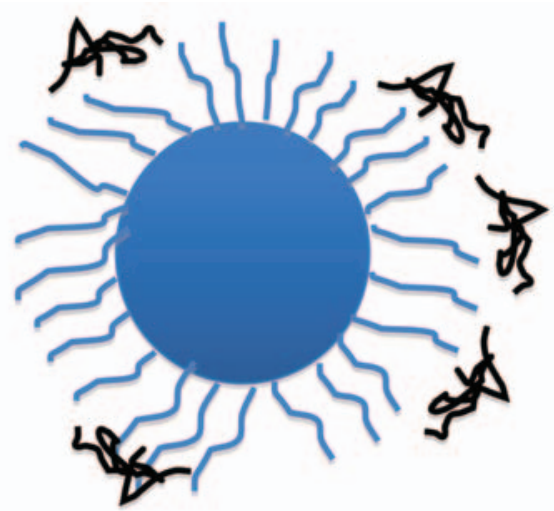

B

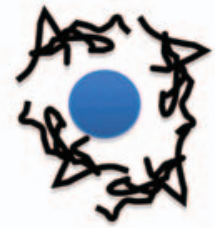

C

Figure 3 - Relation entre la structure des particules et les possibilités de fixation des opsonines sur les nanoparticules dans le plasma sanguin. A - Opsonisation importante B - Opsonisation réduite du fait des molécules hydrophyles de surface qui réalisent un encombrement stérique (exemple pégylation) C - Fixation réduite du fait du rayon de courbure de la particules (particules les plus petites)

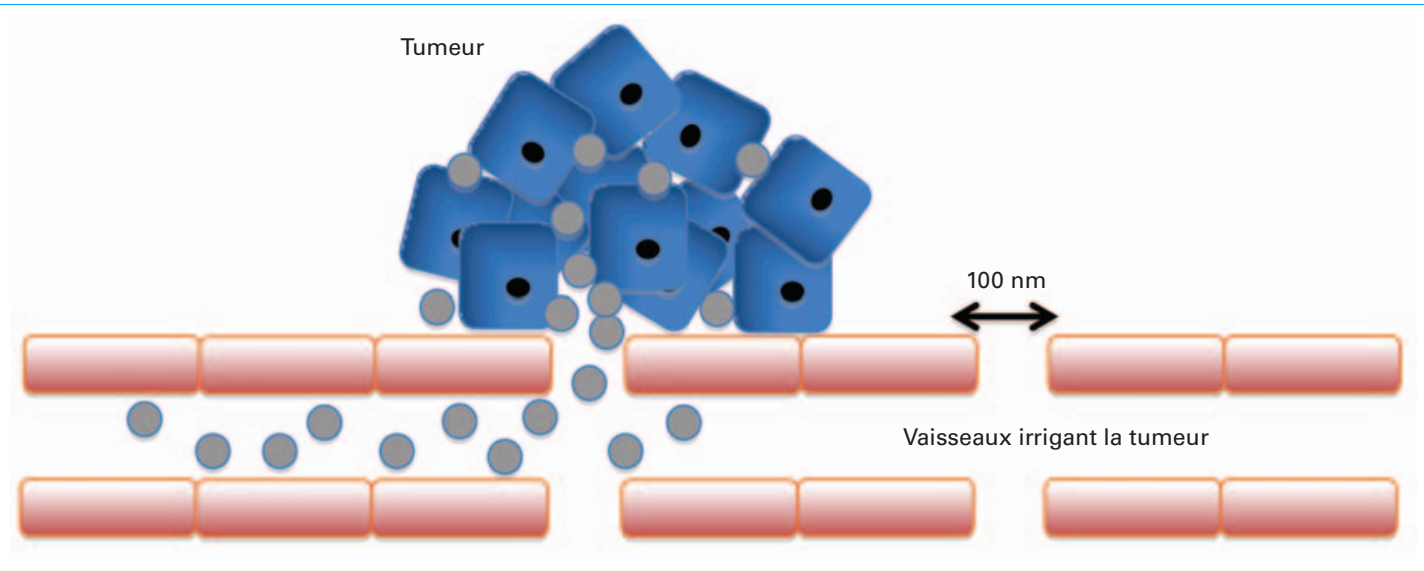

Figure 4 - Schéma de principe du ciblage passif par diffusion des nanoparticules (en gris) dans la tumeur du fait de l'endothélium fenêtré

préliminaire de fixation de protéines sanguines de reconnaissance sur les nanoparticules. Ces protéines appelées opsonines accélèrent donc l'élimination des nanoparticules lorsqu'elles se fixent à leur surface. Les protéines les plus importantes dans ce domaine sont les protéines du système du complément. La fixation de ces protéines à la surface des nanoparticules dépend de plusieurs paramètres. Plus le diamètre des nanoparticules est important, plus les protéines pourront s'y fixer. On considère ainsi que des nanoparticules avec un diamètre $<100 \mathrm{~nm}$ auront du mal à fixer les opsonines. Les surfaces hydrophobes sont un facteur qui favorise l'opsonisation des particules. Ainsi le fait de greffer à la surface des particules des molécules de polyéthylène glycol (PEG) permet non seulement d'augmenter leur hydrophilie mais aussi de limiter I'opsonisation par encombrement stérique (figure 3). La charge électrique de surface des nanoparticules (potentiel zêta) est un facteur qui peut favoriser l'opsonisation. De nombreuses publications dans la littérature traitent de I'effet des modifications de surface sur le temps de circulation des particules (par exemple [8]).

\subsection{Ciblage actif et ciblage passif, effet de rétention et de perméation}

La furtivité des nanomédecines permet un temps de circulation prolongé et ainsi des possibilités de ciblage. On distingue le ciblage passif, qui concerne les vecteurs de première génération et le ciblage actif qui concerne les vecteurs de deuxième et troisième génération en fonction de la cible cellulaire ou intracellulaire respectivement. Le ciblage passif consiste à utiliser des nanoparticules furtives qui vont progressivement s'accumuler dans un tissu selon leurs propriétés de taille et de surface. Ainsi, des nanoparticules de grand diamètres (> $200 \mathrm{~nm}$ ) pourront se retrouver retenues dans la rate ou dans le foie. Le ciblage passif est très utilisé pour atteindre préférentiellement le tissu tumoral. En effet, les tumeurs, sont irriguées par des vaisseaux sanguins à endothélium fenêtré (figure 4) qui pourront laisser passer les particules de diamètre inférieur à $100 \mathrm{~nm}$. Ces particules pourront ainsi pénétrer dans le tissu tumoral et du fait de sa faible pression interstitielle y rester piégées pour finalement libérer le principe actif anticancéreux juste au contact des cellules cibles. Cet effet initialement observé sur des macromolécules [9] a été ensuite mis en évidence avec les nanomédecines [10] et est mis en avant pour expliquer les concentrations plus importantes de nanoparticules que I'on trouve au niveau des tumeurs. Notons ici qu'une molécule de petite taille administrée par voie intraveineuse peut aussi diffuser dans le tissu tumoral, mais alors son faible diamètre l'empêchera de rester dans la tumeur, il rediffusera ensuite vers le sang sans avoir eu la possibilité d'être actif. La taille optimale pour obtenir un bon effet de rétention et de perméation est de 30 à $100 \mathrm{~nm}$. Pour faciliter l'entrée dans les cellules de la tumeur, il est aussi possible de fixer des peptides de pénétration cellulaire à la surface des nanoparticules. Beaucoup de travaux sont actuellement effectués pour trouver 
les peptides les plus efficaces. Certains peptides, comme iRGD, peuvent même être administrés sans être greffés sur les nanoparticules et faciliter la pénétration intratumorale [11].

Le ciblage actif est réalisé à l'aide d'anticorps ou de peptides spécifiques fixés à la surface des particules. On parle ainsi par exemple d'immunoliposomes qui contiennent des anticorps spécifiques leur permettant de se fixer sur des cellules cibles, portant les antigènes correspondants, ou bien de passer certaines barrières comme la barrière hémato-encéphalique. Des nanoparticules ont ainsi été modifiées pour cibler l'endothélium tumoral à l'aide de peptide RGD [12]. Le ciblage actif, bien qu'étant une stratégie très séduisante, est assez difficile à réaliser dans les faits car la spécificité d'interaction ligand/récepteur cellulaire est rare [13], de plus la production industrielle de ce type de nanoparticules modifiées est plus complexe à maîtriser. Ainsi, les nanotechnologies aujourd'hui sur le marché, font appel à du ciblage passif uniquement.

\section{Devenir après administration orale}

\subsection{Rappels de physiologie pour la voie orale}

\subsubsection{De la bouche à l'estomac}

Après administration orale, les nanomédicaments rencontreront la muqueuse buccale et la langue, endroit où il peut théoriquement $y$ avoir une absorption et un passage direct dans le sang. Puis, ils passeront par I'œsophage et arriveront dans l'estomac qui est un milieu assez agressif pour ces formulations du fait d'une acidité importante $(\mathrm{pH}$ entre 1,5 et 5 en fonction du moment de la journée et de la prise concomitante des repas) [14], et des sécrétions gastriques qui contiennent des enzymes comme la lipase gastrique. Le temps de résidence dans l'estomac dépend de nombreux facteurs, le plus déterminant étant la prise de repas. En effet, à jeun, le temps de vidange gastrique peut être très rapide (quelques minutes) si la formulation est prise avec une quantité suffisante de liquide (> $250 \mathrm{ml}$ ). Dans ce cas, I'accès aux zones où le médicament est absorbé (intestin grêle) est plus rapide ce qui contribue à diminuer le délai d'action du médicament. La stabilité des nanomédecines dans l'estomac doit être vérifiée lors du développement industriel, en particulier à l'aide de milieux biomimétiques mimant les conditions chimiques rencontrées par la formulation. II existe ainsi des milieux mimant les liquides gastriques présents dans l'estomac hors des repas (FaSSGF, fasted state simulated gastric fluid) et pendant les repas (FeSSGF, fed state simulated gastric fluid). La composition de ces milieux et leur fabrication sont décrites dans la littérature [15]. La stabilité des nanomédecines dans I'estomac est principalement liée à leur nature (lipidique ou polymère) mais surtout à leur état de surface. II a par exemple ainsi été démontré que la présence de molécules de PEG à la surface des nanoparticules les protégeait de la dégradation [16]. Dans la littérature, on trouve de plus en plus d'exemples d'études de stabilité des nanomédecines au contact des milieux digestifs [17]. En fonction de leur densité par rapport au liquide gastrique, les nanomédecines vont se trouver à la surface du liquide (densité inférieure à celle du liquide gastrique) ou bien dispersées dans son volume (densité égale au liquide gastrique) ou enfin au fond de ce liquide (densité supérieure à celle du liquide gastrique). L'accès au duodénum où pourra commencer l'absorption vers le sang se fait par une zone musculeuse délimitant un sphincter, le pylore. Plus les nanomédecines se trouvent au fond du liquide gastrique, plus elles passeront rapidement le pylore pour atteindre le duodénum où commencera leur absorption vers la circulation sanguine.

\subsubsection{Intestin grêle}

L'intestin grêle est constitué de trois parties, le duodénum, le jéjunum et l'iléon. Ces trois parties correspondent à des structures histologiques un peu différentes. Sur l'épithélium digestif, le type cellulaire le plus courant est l'entérocyte, cellule dotée de microvillosités qui augmentent de façon considérable la surface d'échange avec la lumière du tube digestif. Les autres types cellulaires à considérer pour notre sujet sont les cellules de Paneth qui sécrètent le lysozyme, la phospholipase A2, le TNF alpha et des peptides antibactériens appelés cryptidines; les cellules caliciformes qui sécrètent le mucus, et les cellules $M$ qui surplombent des plaques dites de Peyer correspondant à du tissu lymphoïde diffus.

Ces cellules interagissent à différents niveaux avec les nanomédecines : les enterocytes constituent leur site d'absorption (nous verrons comment au point suivant), les sécrétions des cellules de Paneth peuvent les déstabiliser, le mucus sécrété par les cellules caliciformes constitue une barrière physico-chimique à franchir avant leur absorption par les enterocytes, le passage par les cellules $\mathrm{M}$ permet I'accès direct à la lymphe puis à la circulation sanguine par le canal thoracique qui se jette dans la veine sous-clavière gauche sans passage par le foie.

La lumière du tube digestif dans laquelle arrivent les nanomédecines en sortant de l'estomac contient les liquides digestifs, comme les sécrétions pancréatiques et les sécrétions biliaires en plus des sécrétions cellulaires citées plus haut. Ainsi, les nanomédecines se trouvent dans un environnement qui pourra potentiellement les déstabiliser puis dégrader le principe actif qu'elles renferment. Les enzymes (lipases, colipases, protéases, amylases), les sels biliaires, les ions, les résidus lipidiques et protéiques de l'alimentation réalisent des interactions complexes avec les nanomédecines [16]. C'est pourquoi, comme nous l'avons vu avec les liquides gastriques, il convient d'évaluer la stabilité des nanomédecines au contact de milieux biomimétiques qui miment l'état à jeun (FaSSIF, fasted state simulated intestinal fluid) ou nourri (FeSSIF, fed state simulated intestinal fluid).

\subsubsection{Côlon}

Les nanoparticules qui n'ont pas été absorbées lors du passage dans l'intestin grêle peuvent éventuellement l'être dans le côlon. Certains principes actifs comme les peptides peuvent être plus absorbés à ce niveau du tube digestif s'ils ont été apportés et protégés jusque là. Le côlon contient en effet moins de transporteurs d'efflux ou d'enzymes qui peuvent limiter le processus d'absorption [18]. II faut toutefois garder en mémoire que la surface d'échange ne sera pas aussi importante que dans l'intestin grêle. II existe aussi des raisons de viser des cibles au niveau du côlon du fait de maladies liées à cet organe, comme des maladies inflammatoires digestives par exemple.

\subsection{Processus d'absorption des nanomédecines}

Pour être absorbées et donc passer dans la circulation sanguine afin d'être biodisponibles, les nanomédecines vont devoir franchir 4 types de barrières (figure 5 ). Une barrière chimique dans la lumière intestinale, une barrière physique au travers du mucus, une barrière biologique constituée par l'épithélium digestif et une barrière biochimique du fait des enzymes intracellulaires et des pompes d'efflux (comme par exemple la $\mathrm{P}$ glycoprotéine) présentes sur les entérocytes. Le passage de ces barrières est lié à la stabilité des nanomédecines au cours du processus d'absorption. Cette stabilité est évaluée in vitro ou ex vivo (voir 3.3). Le processus d'absorption est réalisé du fait des propriétés diffusives ou adhésives des nanomédecines au travers des 4 barrières citées plus haut. La diffusion est fonction de la taille des nanovecteurs, de leur état de surface et de leur charge [19], en particulier au niveau du mucus qui peut constituer un frein significatif à l'absorption pour des particules de taille supérieure à $500 \mathrm{~nm}$ [20]. Le passage de l'épithélium 


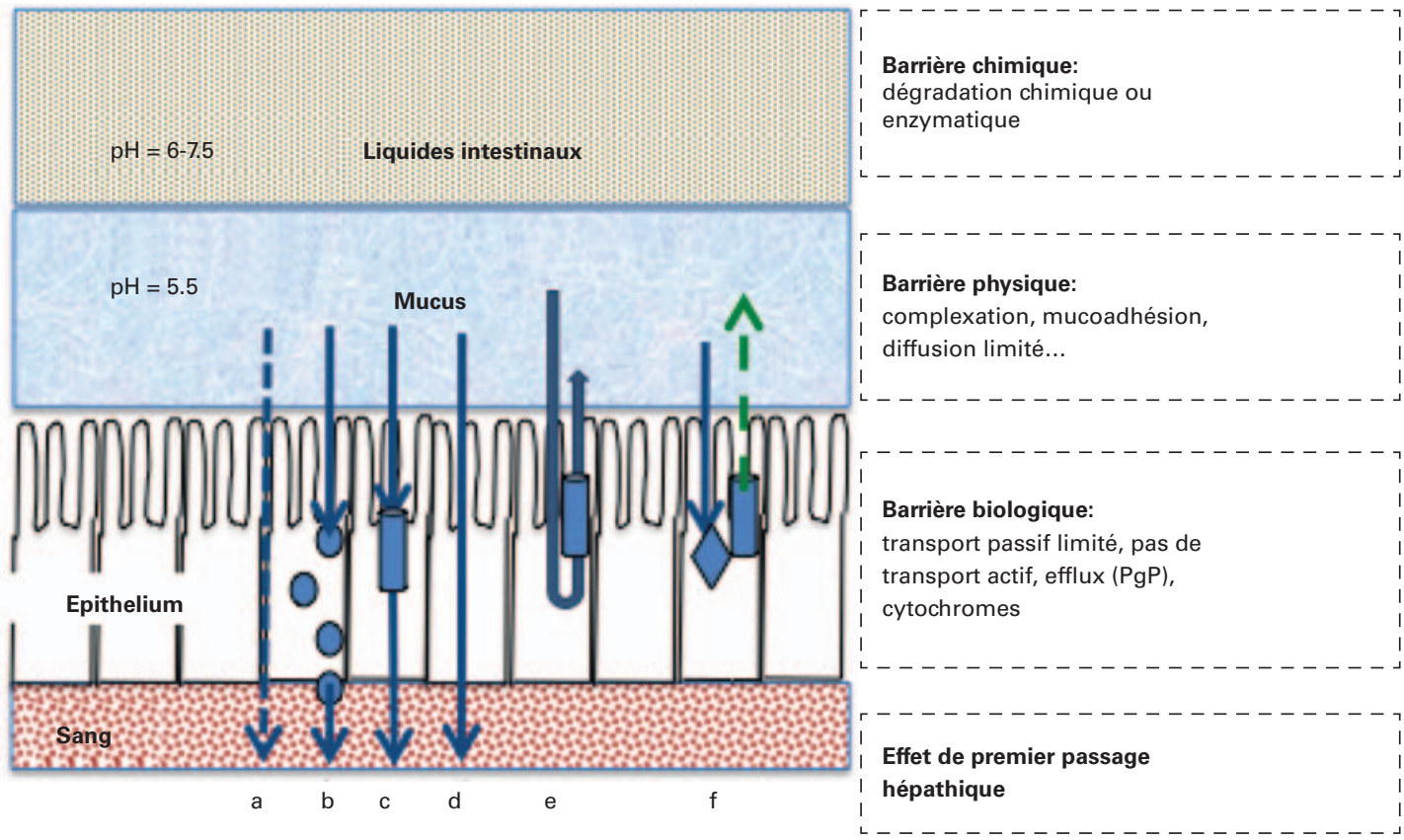

Figure 5 - Barrières à franchir pour le médicament après absorption par voie orale et processus d'absorption : transport paracellulaire (a), endocytose (b), transport actif (c), diffusion passive (d). Oppositions à I'absorption : pompe d'efflux (e), métabolisme suivi de l'efflux du métabolite généré (f)

digestif est réalisé par endocytose. En effet, les nanomédecines sont de trop grande taille pour passer par voie paracellulaire, c'est-à-dire dans l'espace de quelques nanomètres laissé entre les cellules scellées par des jonctions serrées de type zonula occludens et zonula adherens. Quelques études controversées ont avancé le passage possible par voie paracellulaire lorsque les complexes de jonctions étaient déstabilisés par des excipients présents dans les nanoparticules. Le passage direct par voie transcellulaire par transport passif fait appel à un processus diffusif suivant la loi de Fick. Ce mécanisme est réservé aux petites molécules (masse moléculaire < $1000 \mathrm{Da}$ environ) lipophiles (logP optimal entre 1,5 et 3). Ainsi, les nanomédecines, trop grosses et à surface souvent hydrophile, doivent être internalisées dans les entérocytes par une autre voie : I'endocytose. II existe trois mécanismes d'endocytose possible : l'endocytose médiée par des vésicules (puits) tapissées de clathrine, I'endocytose liée aux radeaux (rafts) lipidiques et I'endocytose médiée par d'autres protéines membranaires, les cavéolines. En fonction de leur taille et de leur propriétés chimiques de surface, les nanovecteurs peuvent prendre une ou plusieurs de ces voies d'internalisation. Le devenir des nanomédecines dans le cytosol (passage par les lysosomes ou non) est alors différent en fonction des voies utilisées pour pénétrer dans la cellule [16]. II faut distinguer alors deux cas de figure :

- le nanovecteur est absorbé intact dans la cellule et y reste stable (ou légèrement modifié) pour être libéré au pôle opposé (transcytose) et passer ainsi dans la circulation sanguine ;

- le nanovecteur est détruit dans la cellule, le principe actif est libéré et peut ou non être métabolisé dans la cellule (par exemple par les cytochromes) et finalement passer dans la circulation sanguine.

L'absorption des nanomédecines par voie orale est donc un processus difficile, semé d'embûches. II est ainsi important lors du développement de ces nouveaux médicaments d'évaluer et de déterminer les mécanismes de leur absorption afin de détenir des informations pour optimiser leurs performances.

\section{3 Évaluation des performances des nanomédecines pour la voie orale}

La stabilité des nanomédecines au contact de la barrière chimique est évaluée par des études in vitro. Ces études consistent à mettre en contact des nanovecteurs avec des milieux biomimétiques représentatifs de l'estomac ou de l'intestin grêle correspondants aux états physiologiques " à jeun " et " nourri " comme décrit plus haut. Au bout d'un temps déterminé (classiquement $3 \mathrm{~h}$ pour l'estomac et $6 \mathrm{~h}$ pour l'intestin) la stabilité des nanoparticules est évaluée. Pour cela, on mesure leur taille par diffraction de la lumière et leur charge en principe actif après le temps d'incubation au contact des milieux biomimétiques. La stabilité est vérifiée si la taille moyenne et l'indice de polydispersité ne sont significativement différents de leur valeurs initiales (utilisation d'un test statistique approprié) et bien entendu, si la charge en principe actif (sa concentration dans le vecteur) est restée proche de $100 \%$ de la charge initiale (une valeur de $90 \%$ est souvent considérée comme le seuil de stabilité). Ces études de stabilité peuvent être complétées par d'autres évaluations (couleur, $\mathrm{pH}$, osmolarité, turbidimétrie...) visant à vérifier le maintien dans le temps des propriétés de la formulation en s'inspirant de la conférence de consensus $\mathrm{ICH}$ Q2A qui dépasse le champ des nanomédecines et constitue un guide général pour les études de stabilité.

La capacité des nanomédecines à diffuser dans la barrière physique qu'est le mucus est évaluée par des modèles de diffusion en 3 dimensions (dans une épaisseur standard de mucus) ou en 2 dimensions comme cela a été récemment proposé [21].

Pour cela, il est possible de mesurer la diffusion dans des puits de type transwell ${ }^{\circledR}$ (figure 6) ou par des techniques de " particle tracking " ou enfin par suivi de la réapparition de fluorescence après exctinction (FRAP, fluorescence recovery after photobleaching). Quelle que soit la technique utilisée, il est important de noter que la source de mucus utilisée (humaine ou animale), le type de mucus (digestif, bronchique, cervical...), les conditions 


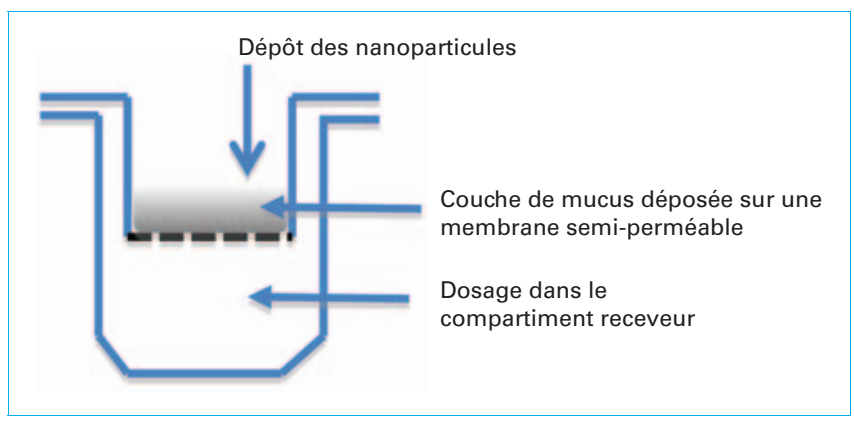

Figure 6 - Schéma du système transwell ${ }^{\circledR}$ utilisé dans les études de diffusion au travers de couches cellulaires ou de mucus

expérimentales des études de diffusion (concentration, durée de l'expérience, travail ou non à l'équilibre...) vont avoir une incidence importante sur les résultats de l'expérience (pour une information détaillée sur les modèles de mucus et les conditions expérimentales voir [22]).

Le passage des barrières biologiques et biochimiques constituées par les cellules épithéliales (en grande majorité les entérocytes où l'absorption a lieu) est évalué à l'aide de cultures cellulaires sur des plaques multipuits de type transwell ${ }^{\circledR}$ (figure 6). Des cellules Caco-2 provenant d'une lignée tumorale de cancer de colon sont classiquement utilisées pour évaluer le passage des médicaments au travers de l'épithélium digestif. Cette technique est bien adaptée à l'évaluation des nanomédecines. Les cellules se différencient en entérocytes en 21 jours et ont un phénotype biochimique proche des cellules humaines avec toutefois des différences notables, par exemple les jonctions serrées sont moins nombreuses, l'activité PgP est plus importante et l'activité cytochrome P450 n'est pas superposable à celle des entérocytes sains. II est possible d'utiliser des clones de cellules Caco-2 se rapprochant un peu plus des entérocytes humains comme le clone TC7. Les cellules Caco-2 ne sécrétant pas de mucus, il est possible de faire des cocultures avec des cellules HT29-MTX qui pourront produire ce mucus et donc mieux mimer l'épithélium intestinal. En screening, il est parfois difficile d'attendre 21 jours pour obtenir des résultats de perméabilité, il est alors possible d'utiliser des cellules MDCK, cellules rénales de chien, qui se différencient en entérocytes en 3 jours. Pour réaliser ces essais de perméabilité, on cultive les cellules en monocouche, puis on dépose la suspension de nanoparticules à tester côté apical, on dose ce qui apparaît au niveau basolatéral et on calcule le coefficient de perméabilité apparente $\left(P_{a p p}\right)$ avec la formule suivante :

$$
P_{\text {app }}=\mathrm{d} Q / \mathrm{d} t \times 1 / A C_{0}
$$

avec $\mathrm{d} Q / \mathrm{d} t$

vitesse d'apparition du principe actif au pôle apical des cellules,

$$
\begin{array}{ll}
A & \text { aire de la culture cellulaire, } \\
C_{0} & \text { concentration au temps initial. }
\end{array}
$$

Afin de déterminer si des transports actifs sont impliqués dans le transport des nanoparticules (ou du principe actif libéré), il est possible de réaliser l'expérience à $4{ }^{\circ} \mathrm{C}$, température où le transport actif est inhibé et comparer les résultats à ceux obtenus à $37{ }^{\circ} \mathrm{C}$. Le transport actif sera évalué par différence en négligeant toutefois la différence de fluidité membranaire à basse température limitant de fait la diffusion passive. Le fait de réaliser des essais de transport en sens opposé à l'absorption (basolatéral vers apical) permet aussi d'avoir une idée de l'implication des protéines d'efflux comme la PgP dans l'interférence avec le transport. En effet, un transport significativement plus important dans le sens opposé à l'absorption signera une activité des pompes d'efflux. Lors de ces expériences il est important de suivre la résistance transépithéliale (résistance au passage ionique suite à l'application d'une différence de potentiel de part et d'autre de la couche cellulaire) qui est le témoin de l'intégrité de la couche cellulaire. Un abaissement brutal de cette résistance est le signe d'une dégradation de la bicouche et invalide I'essai en cours. La résistance transépithéliale est aussi mesurée pour déceler les effets des nanomédecines ou de leurs excipients sur l'intégrité des jonctions serrées participant à la qualité de la barrière cellulaire. Lors de I'utilisation des monocouches cellulaires, il est aussi primordial de calculer les perméabilités apparentes lors du passage de molécules témoins comme le labétalol ou le propranolol afin de qualifier le modèle cellulaire utilisé et les conditions expérimentales.

Les performances des nanomédecines sont aussi évaluées sur I'animal entier, par exemple à l'aide de modèle perfusion intestinal (in situ, single pass intestinal perfusion model), ou bien après gavage et mesure des concentrations sanguines par une étude de pharmacocinétique classique.

\subsection{Principales applications des nanomédecines utilisées par voie orale}

Les principales applications des nanomédecines utilisées par voie orale concernent les principes actifs classés en classe II et IV de la classification BCS (biopharmaceutical classification system) proposé par LG Amidon en 1995 [23]. Ce sont des principes actifs peu solubles (classe II) qui peuvent être en plus peu perméables au travers de l'épithélium digestif (classe IV). L'encapsulation dans des nanoparticules permet de fait d'augmenter leur solubilité (du moins la solubilité apparente) et peut aussi augmenter l'internalisation dans les entérocytes. II existe aussi des applications d'encapsulation de molécules fragiles dans des nanoparticules, ceci dans un but de protection avant absorption. C'est par exemple le cas de molécules biologiques telles que l'insuline [24] ou de polysacharrides comme le fondaparinux [25]. De nombreuses publications décrivent des formulations particulaires pour la voie orale et permettent de démontrer une augmentation de biodisponibilité après nano-encapsulation [16], mais aucune spécialité n'est aujourd'hui sur le marché.

\section{Devenir après administration cutanée}

\subsection{Rappel de physiologie de la peau}

La peau est constituée de 3 tissus superposés (figure 7). Le plus externe, l'épiderme, est constitué du stratum corneum, épithélium pavimenteux stratifié kératinisé en perpétuel renouvellement et du stratum germinativum, plus profond, qui contient les cellules qui formeront à terme le stratum corneum. L'épiderme permet une protection mécanique et biochimique et constitue la première barrière à franchir pour les médicaments administrés sur la peau. Le second, plus lâche, est le derme. Ce tissu contient des vaisseaux sanguins et du tissu conjonctif, la diffusion des molécules y est facilitée. Le plus profond, I'hypoderme, contient du tissu conjonctif mais aussi de la graisse dans laquelle peuvent se nicher des molécules lipophiles. Á la surface de la peau, on trouve aussi la terminaison des canaux sudoripares et les follicules pilo-sébacés qui peuvent être des portes d'entrée du médicament dans I'organisme. La surface de la peau est très faible comparativement à la surface de l'épithélium digestif $\left(2 \mathrm{~m}^{2}\right.$ contre $200 \mathrm{~m}^{2}$ ) ce qui limite les possibilités d'absorption de principe actif avec un fort débit d'entrée dans I'organisme. 


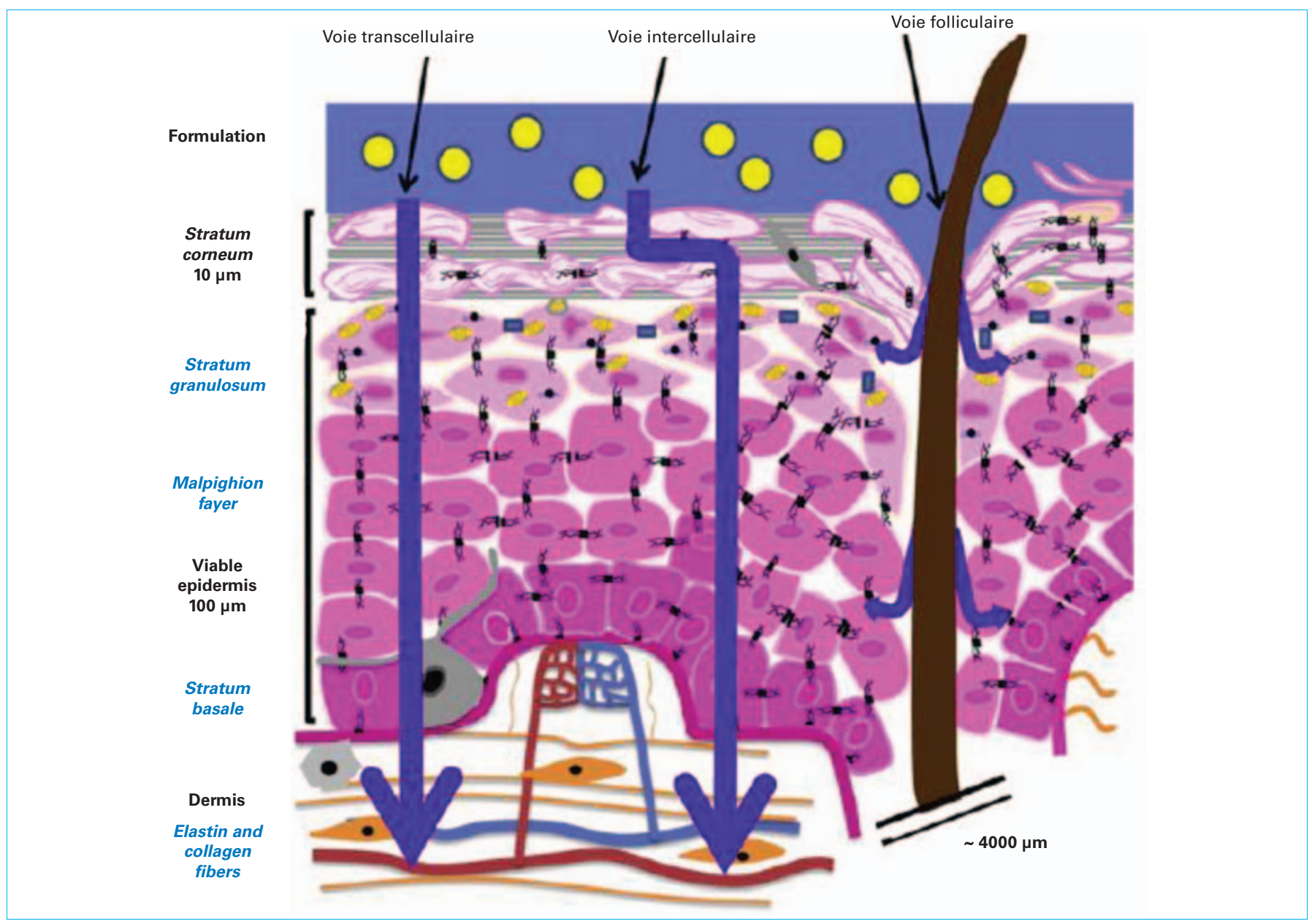

Figure 7 - Structures et voies de passage au travers de la peau (d'après Bolzinger et al.)

\subsection{Mécanismes de passage des nanoparticules au travers de la peau}

Très peu de nanoparticules ont montré une bonne pénétration cutanée jusqu'aux tissus les plus profonds. En effet, l'épiderme avec ses couches cellulaires, peu riches en eau, superposées, est difficile à traverser pour les nanoparticules. Les nanoparticules pénètrent dans la peau par des phénomènes diffusifs qui dépendent de leur concentration à la surface de la peau, mais aussi de leur taille [26], de leurs charges électriques et de leur hydrophobicité de surface. Les particules les plus petites et les plus hydrophobes passent le mieux. II est utile ici de rappeler que les canaux lipidiques, par lesquels les nanoparticules pourraient diffuser, ont une taille évaluée à $19 \mathrm{~nm}$ [27]. II existe trois grandes voies pour traverser la peau (figure 7). La voie transcellulaire qui fait appel à une diffusion directe au travers des couches successives de cellules. Cette voie est peu adaptée aux nanoparticules qui doivent successivement se partager entre les bicouches de phospholipides des membranes cellulaires et les cytosols des cellules. Les phénomènes d'endocytose sont, de plus, ici moins efficaces que dans les entérocytes. La voie intercellulaire, fait appel à une diffusion entre les cellules par les espaces interstitiels mais aussi vraisemblablement par les bicouches de phospholipides. Dans ce dernier cas, des nanoparticules de petites tailles, à surface hydrophobe, peuvent théoriquement diffuser. La troisième voie de pénétration cutanée se fait le long du follicule pilo-sébacé à la base des poils de la peau. Cette voie est la plus adaptée aux nanoparticules. On a d'ailleurs, le plus souvent, retrouvé les nanoparticules marquées le long du follicule pilo-sébacé, jusque à la racine des poils. À cet endroit il est ensuite possible que les nanoparticules diffusent dans le derme. Alors que les voies transcellulaires et intercellulaires laissent peu de possibilités au passage de nanoparticules de tailles supérieures à $20 \mathrm{~nm}$, le passage de particules de taille beaucoup plus importante a été rapporté par la voie folliculaire (jusqu'à $600 \mathrm{~nm})[28]$.

\section{3 Évaluation des performances des nanomédecines appliquées sur la peau}

Le passage des nanomédecines au travers de la peau peut être évalué in vitro ou in vivo. Les techniques in vitro font appel à des cultures cellulaires spécifiques. On utilise des cultures primaires issues de prélèvements cutanés qui permettent de reconstituer l'épiderme ou le derme. La structure de la peau étant complexe, il est difficile d'obtenir des modèles cellulaires très pertinents. II y a en effet nécessité de cultiver les cellules sur plusieurs couches (culture 3D) avec des cellules de natures différentes (fibroblastes, keratonocytes) pour mimer les différents étages de la peau. II existe des modèles prêt à l'emploi disponibles dans le commerce (Epiderm ${ }^{\circledR}$ ). 


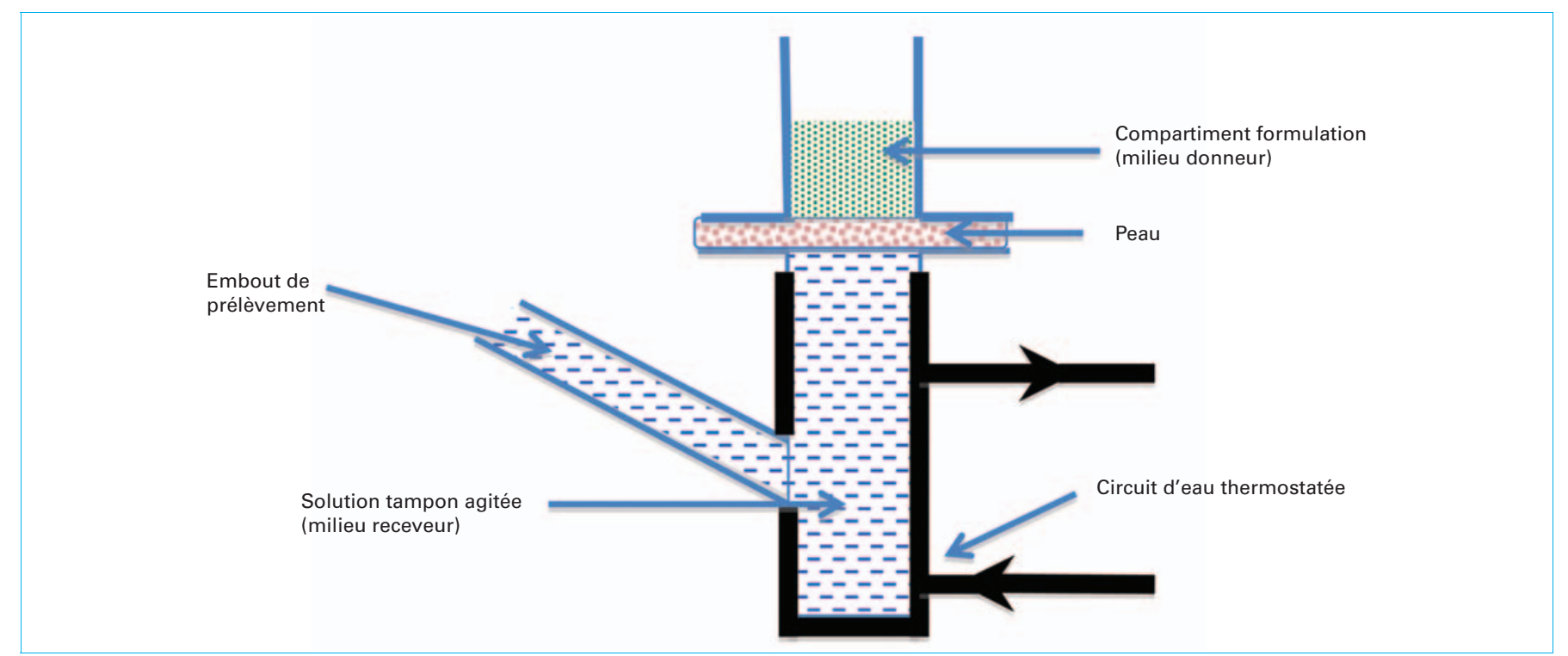

Figure 8 - Schéma d'une cellule de Franz pour l'étude du passage transcutané

Du fait de la complexité à réaliser de bons modèles cellulaires, il est le plus souvent fait appel aux prélèvements de peau sur des hommes ou des animaux. Il est possible d'utiliser, par exemple, de la peau d'oreille de porc qui mime assez bien la peau humaine. Les peaux prélevées vont être placées sur un dispositif qui permettra la mesure de diffusion au travers du tissu. On utilise pour cela des cellules de Franz (figure 8). Ces cellules permettent les études de diffusion sur plusieurs heures. Il est aussi possible d'observer la pénétration de nanoparticules marquées, dans l'épaisseur de la peau par microscopie. L'utilisation des cellules de Franz permet une comparaison des formulations entre elles mais peut parfois se révéler assez peu prédictive. En effet, le milieu receveur dans lequel les nanoparticules sont dosées après diffusion au travers de la peau peut influencer le processus de diffusion en fonction de la dispersibilité des nanoparticules dans ce milieu : si le milieu permet une bonne dispersion des nanoparticules, il facilitera le processus de diffusion, I'inverse étant aussi vrai. Ce modèle ex vivo, ne prend pas non plus en compte la circulation sanguine, il est donc plus réservé à l'étude de formulations pour lesquelles la délivrance systémique n'est pas recherchée (délivrance locale uniquement).

Pour mesurer la pénétration des principes actifs au travers de la peau, il est possible d'utiliser des techniques de microdialyse sur animal vivant ou sur volontaire sain. Dans ce cas, on détecte la molécule active mais pas la présence de nanoparticules. Un cathéter dont les parois sont semi-perméables est implanté à une profondeur déterminée dans la peau (par exemple au niveau du derme profond). Dans ce cathéter, on fait passer une solution tampon dans laquelle la molécule à doser sera bien soluble. Ce tampon en passant dans le cathéter va recevoir la molécule par diffusion. La concentration mesurée en sortie de cathéter sera reliée à la concentration tissulaire. Ces techniques, bien que très informatives, nécessitent une validation importante (choix du cathéter, de la solution tampon, réglage des débits, validation de la procédure analytique etc.). Afin d'objectiver le passage sanguin suite à l'application cutanée d'une formulation de nanoparticules, seules les études de pharmacocinétiques faisant appel à des prélèvements de sang pourront être une bonne méthode de quantification.

Lorsque l'on s'intéresse à la pénétration cutanée de nanoparticules transportant des médicaments, il est intéressant de mesurer leur stabilité dans les différentes couches de la peau, c'est-à-dire tout au long de leur trajet d'absorption. Pour cela, on utilise des techniques de FRET comme décrit plus haut dans le cas de la voie orale.

Il faut noter que le passage des nanoparticules dans les couches profondes de la peau reste controversé. En fonction du type de nanoparticules, du modèle utilisé (peau vivante d'origine humaine ou animale, tissu isolé, échantillon prélevé sur cadavre) et des modalités expérimentales (imagerie, dosage des molécules ou des constituants des particules etc.), les résultats observés peuvent être très différents [28].

\subsection{Applications de I'utilisation des nanomédecines appliquées sur la peau}

De nombreuses publications rapportent I'utilisation des nanoparticules pour traiter les affections cutanées. En effet, les nanoparticules peuvent augmenter la diffusion de principe actifs qui seraient trop hydrophiles $(\log \mathrm{P}<2$ ) ou trop gros (masse moléculaire supérieure à $500 \mathrm{Da}$ ) pour diffuser librement dans les structures de la peau. Les nanoparticules peuvent aussi protéger les principes actifs de la dégradation chimique par les enzymes présentes au niveau cutané. De nombreuses formulations nanoparticulaires ont ainsi été évaluées pour leur passage transcutané (liposomes, nanoparticules lipidiques solides, nanocapsules lipidiques, nanoparticules de polymères, des dendrimères, des nanogels etc.) pour transporter une grande variété de molécules (antifongiques, anti-inflammatoires, immunosupresseurs, etc.). Les maladies ciblées sont les infections de la peau et les maladies inflammatoires chroniques comprenant ou non une composante immnunitaire [27]. II existe aussi des applications en cancérologie, pour les traitements par exemple des mélanomes. Dans ce cas la pénétration des nanoparticules doit être plus importante, en particulier dans les tissus tumoraux. En cancérologie, il est possible de vectoriser des anticancéreux dans les structures cutanées à l'aide de nanomédecines, mais des études récentes visent aussi à modifier le phénotype des cellules tumorales pour les rendre plus sensibles aux molécules cytotoxiques, par exemple à l'aide de nanoparticules apportant des ARN interférents qui bloqueront certaines protéines nécessaires à la prolifération ou à la chimio résistance de ces cellules [29] ou de I'ADN pour transfecter les cellules tumorales en un phénotype plus sensible aux chimiothérapies [30]. 


\section{Devenir après administration pulmonaire}

\subsection{Rappels physiologiques du poumon}

Le poumon a pour rôle d'oxygéner le sang en lui apportant l'oxygène de l'air et en lui permettant d'éliminer le dioxyde de carbone. Les canaux qui transportent ces gaz sont les bronches puis les bronchioles. L'arbre pulmonaire comprend 23 bifurcations pour passer des plus grosses bronches aux bronchioles et parvenir aux alvéoles pulmonaires où se font les échanges gazeux. Au niveau proximal, l'épithélium est pseudostratifié et composé de cellules cillées ainsi que de cellules caliciformes qui sécrètent du mucus. L'épithélium s'amincit ensuite pour être très fin au niveau des alvéoles pulmonaires. II est alors composé de deux types cellulaires, les pneumocytes de type I ( $95 \%$ des cellules) et les pneumocytes de type II qui produisent le surfactant et sont les précurseurs des pneumocytes de type I. Le surfactant est une substance qui forme un film sur les alvéoles et les empêche de se collaber. II est composé de $80 \%$ de phospholipides et $5-10 \%$ de lipides neutres auxquels s'ajoutent $10 \%$ de protéines dont plus de la moitié sont spécifiques du surfactant. Le mucus présent dans les bronches et les bronchioles a une épaisseur de 5 à $55 \mu \mathrm{m}$ et est constitué comme le mucus intestinal en majorité d'eau (95\%) et de mucines $(2 \%)$ associées à d'autres protéines, ions lipides et sels. Le mucus est éliminé en permanence par les cellules ciliées après avoir piégé les grosses particules (clairance mucociliaire). La profondeur de pénétration des particules dans l'arbre pulmonaire dépend de leur taille. Plus les particules respirées sont petites, plus elles peuvent atteindre facilement les alvéoles. Les particules de tailles supérieures à $5 \mu \mathrm{m}$ ne parviennent pas aux alvéoles et s'impactent dans les bronches ou bronchioles après inhalation. Par contre, si elles sont trop petites $(<0,1 \mu \mathrm{m})$, les particules peuvent aussi être expirées plus facilement. On considère ainsi qu'un diamètre aérodynamique de 1-2 $\mu \mathrm{m}$ permet une bonne pénétration et une certaine rémanence dans les alvéoles. La surface totale des alvéoles est de $100 \mathrm{~m}^{2}$ environ, ce qui est un facteur favorable à la diffusion vers le sang en cas de bonne perméabilité du principe actif.

\subsection{Devenir des nanomédecines dans le poumon}

Lorsque des nanomédecines sont inhalées, leur taille leur permet $\mathrm{d}^{\prime}$ atteindre les alvéoles pulmonaires et donc théoriquement de diffuser dans le sang. II faut ici noter que ces colloïdes sont souvent administrés sous forme d'aérosol, c'est donc la taille des gouttelettes d'aérosol qu'il faudra considérer pour influencer la profondeur de pénétration et la rémanence dans les alvéoles pulmonaires et non la taille des nanoparticules elles-mêmes. Pour parvenir aux alvéoles, il faut que les nanoparticules évitent de rester bloquées dans la couche de mucus qui tapisse bronches et bronchioles. Ainsi les formes trop mucoadhésives risquent de rester dans la première partie de l'arbre pulmonaire. Ensuite, les nanoparticules doivent pouvoir être stable au contact du surfactant et diffuser dans ce liquide si particulier. Alors, les colloïdes pourront potentiellement diffuser dans le sang. Les nanomédecines qui agrègent peu les mucines et les protéines du surfactant ont une meilleure stabilité et un meilleur pouvoir de pénétration dans les alvéoles pulmonaires. Les macrophages alvéolaires constituent une barrière efficace à la pénétration des grosses molécules comme des protéines $(>30 \mathrm{kDa})$. II faut toutefois noter que les petites protéines comme I'insuline $(5,8 \mathrm{kDa})$ et les nanoparticules de petites tailles $(<200 \mathrm{~nm})$ peuvent être épargnées par les macrophages pulmonaires selon certains auteurs [31]. Les nanoparticules sont difficilement absorbées intactes vers le sang par voie pulmonaire, après instillation il en est retrouvé une minorité dans le foie. La plus grande partie de la dose reste en effet dans les alvéoles. Les plus petites nanoparticules $(<34 \mathrm{~nm})$ lorsqu'elles ne sont pas cationiques peuvent passer dans la lymphe puis théoriquement dans le sang. Lorsque leur taille est inférieure à $6 \mathrm{~nm}$, les nanoparticules passent dans la lymphe indépendamment de leur charge et peuvent passer directement dans le sang par passage paracellulaire.

\subsection{Principaux modèles d'évaluation des nanomédecines utilisées par voie pulmonaire}

Les modèles d'évaluation des nanomédecines administrées par voie pulmonaire ne sont pas spécifiques au type de formulation utilisée. En effet, de nombreux modèles, qui ont été historiquement mis au point pour évaluer le devenir des molécules dans l'arbre pulmonaire et leur capacité à être absorbées dans le sang, sont utilisés dans le cadre de la mise au point des nanomédecines.

Pour évaluer l'interaction directe entre les nanomédecines et les cellules constituant le système pulmonaire, il est très souvent fait appel aux cultures cellulaires 32. Les lignées utilisées sont, par exemple, A427, A549, HBE14o et les lignées calu-1, -2, -3. Chaque lignée mime un type cellulaire particulier, ainsi, les A549 miment les pneumocytes de type II et servent à explorer I'absorption alvéolaire, les calu-3 et les HBE14o modélisent les cellules de l'épithélium bronchique. Comme tous les modèles in vitro, ces lignées cellulaires ne permettent que d'avoir une vue approximative et tronquée des interactions médicament/organisme (absence de mucus et de surfactant par exemple), ceci est d'autant plus vrai avec les nanoparticules. Pour augmenter le pouvoir prédictif des modèles, on utilise des modèles ex vivo ou in vivo [33]. Le modèle ex vivo le plus utilisé est le modèle de poumon isolé et perfusé le plus classiquement de rat ou de cochon d'Inde. Ces modèles restent toutefois peu prédictifs pour certaines molécules, assez difficiles à mettre en place et permettent de ne tester qu'un petit nombre d'échantillons. Pour augmenter encore le pouvoir prédictif des modèles, il est fait appel aux animaux vivants (rats, cochon d'Inde, lapin, chien beagle, singe rhésus) qui ont une physiologie plus ou moins proche de celle de I'homme (pour une comparaison précise des caractéristiques interespèce, voir [33]). Dans ces modèles, les principes actifs sont administrés par inhalation passive dans des chambres spécifiques ou bien à l'aide de dispositifs de vaporisation (" sprayer "). La deuxième méthode permet de traiter plus d'animaux mais reste considérée comme moins pertinente pour l'extrapolation de résultats aux thérapeutiques humaines. La méthode d'administration utilisée doit être validée, qualifiée et est considéré comme un des facteurs clé de l'expérimentation car ayant une grande influence sur le résultat de l'étude (reproductibilité en particulier). Pour ces modèles animaux, l'évaluation fait appel a des études de pharmacocinétique, après dosages sanguins ou dans le liquide broncho-alvéolaire, voire dans les tissus pulmonaires, mais aussi, très souvent à des techniques d'imagerie qui permettent de déterminer la profondeur de diffusion de la dose administrée dans l'arbre pulmonaire.

\subsection{Applications de I'utilisation des nanomédecines administrées par voie pulmonaire}

Les nanomédecines destinées à l'administration pulmonaire on trois objectifs distincts, mais parfois liés. Premièrement, de permettre la formulation d'un aérosol pour des molécules qui seraient trop fragiles ou trop lipophiles pour ce type de formulation inhalée. Deuxièmement, d'augmenter la quantité de molécule active qui parvient aux alvéoles et son temps de présence, ce qui est important pour le traitement d'affections locales des poumons. Troisièmement, d'augmenter la diffusion systémique après instillation pulmonaire de molécules qui seraient peu absorbées si 
administrée par des formulations classiques. Dans ce cas, augmenter le temps de résidence dans les alvéoles et la concentration en principe actif favorise les phénomènes de diffusion passive vers le sang.

Les nanomédecines peuvent ainsi être utilisées pour le traitement de maladies pulmonaires comme l'asthme, I'hypertension pulmonaire, la mucoviscidose, les infections, les cancers pulmonaires. Les principes actifs sont ainsi issus de multiples familles : antibiotiques, immunomodulateurs, anti-inflammatoires, vaccins... pour une liste complète (voir [32]). II existe quelques formes nanoparticulaires sur le marché ou en essais cliniques avancés. Ainsi, des liposomes pour inhalation contenant de l'amikacine, destinés aux infections pulmonaires à bacille Gram négatifs (présents par exemple en cas de mucoviscidose), sont proches de la commercialisation. II existe aussi une forme liposomale de ciprofloxacine en essai clinique [31]. Les nanomédecines sont aussi très prometteuses pour réaliser une thérapie génique (à I'aide de I'ADN ou d'ARN interférent) qui serait par exemple importante pour le traitement de la mucoviscidose, maladie causée par des mutations génétiques (régulation des transports d'ions transmembranaires).

\section{Conclusion}

Le devenir des nanomédecines dans l'organisme dépend de leurs caractéristiques physiques et chimiques mais aussi des structures tissulaires qu'elles rencontrent. Ainsi, il apparaît aujourd'hui qu'une connaissance approfondie de la physiologie, de l'histologie, de la biochimie et des mécanismes de biologie moléculaire est indissociable des connaissances technologiques lorsque I'on cherche à développer des nanomédicaments performants. À l'avenir, le ciblage des médicaments à l'aide de nanoparticules sera de plus en plus fin. Aujourd'hui, le ciblage des organites cellulaires commence à être recherché pour augmenter encore l'efficacité et diminuer la toxicité des molécules actives. Le devenir des nanomédecines au sein de la cellule est étudié et parfois modifié pour servir encore plus les objectifs du thérapeute. II reste toutefois un défi important, c'est la production de ces nouveaux médicaments en milieu industriel avec les critères qualité de l'industrie pharmaceutique, leur évaluation clinique et leur mise sur le marché à un coût compatible avec une large utilisation par les malades du monde entier. 


\title{
Devenir des nanoparticules utilisées comme médicament dans l'organisme
}

\author{
par Frédéric LAGARCE \\ Professeur de biopharmacie \\ Faculté de pharmacie \\ Inserm, U 1066 MINT, LUNAM Université, Angers, France
}

\section{Sources bibliographiques}

[1] SHEGOKAR (R.), SINGH (K.K.) et MULLER (R. H.). - Production \& stability of stavudine solid lipid nanoparticles - from lab to industrial scale. Int J Pharm, 416, p. 461-470 (2011).

[2] HUYNH (N.T.), PASSIRANI (C.), SAULNIER (P.) et BENOIT (J.P.). - Lipid nanocapsules : a new platform for nanomedicine. Int J Pharm, 379 , p. 201-209 (2009).

[3] HUREAUX (J.), LAGARCE (F.), GAGNADOUX (F.), CLAVREUL (A.), BENOIT (J.P.) et URBAN (T.). - The adaptation of lipid nanocapsule formulations for blood administration in animals. Int J Pharm, 379, p. 266-269 (2009).

[4] THOMAS (O.) et LAGARCE (F.). - Lipid nanocapsules : a nanocarrier suitable for scale-up process. Journal of drug delivery science and technology, 23, p. 555-559 (2013).

[5] XIE (J.), LEE (S.) et CHEN (X.). - Nanoparticle-based theranostic agents. Adv Drug Deliv Rev, 62, p. 1064-1079 (2010).

[6] DAVIES (B.) et MORRIS (T.). - Physiological parameters in laboratory animals and humans. Pharm Res, 10, p. 1093-1095 (1993).

[7] BERTRAND (N.) et LEROUX (J.C.). - The journey of a drug-carrier in the body : an anatomo-physiological perspective. J Control Release, 161, p. 152-163 (2012).

[8] OWENS (D.E.), 3RD et PEPPAS (N.A.). Opsonization, biodistribution, and pharmacokinetics of polymeric nanoparticles. Int J Pharm, 307, p. 93-102 (2006).

[9] MATSUMURA (Y.) et MAEDA (H.). - A new concept for macromolecular therapeutics in cancer chemotherapy : mechanism of tumoritropic accumulation of proteins and the antitumor agent smancs. Cancer Res, 46, p. 6387-6392 (1986)

[10] DANHIER (F.), FERON (O.) et PREAT (V.). - To exploit the tumor microenvironment : Passive and active tumor targeting of nanocarriers for anti-cancer drug delivery. $\mathrm{J}$ Control Release, 148, p. 135-146 (2010).

[11] SUGAHARA (K.N.), TEESALU (T.), KARMALI (P.P.), KOTAMRAJU (V.R.), AGEMY (L.), GREENWALD (D.R.) et RUOSLAHTI (E.). - CoGREENWALD (D.R.) et RUOS
administration of a tumor-penetrating peptide enhances the efficacy of cancer drugs. Science, 328, p. 1031-1035 (2010).

[12] DANHIER (F.), VROMAN (B.), LECOUTURIER (N.), CROKART (N.), POURCELLE (V.), FREICHELS (H.), JEROME (C.), MARCHAND-BRY-
NAERT (J.), FERON (O.) et PREAT (V.). - Targeting of tumor endothelium by RGD-grafted PLGA-nanoparticles loaded with paclitaxel. J Control Release, 140, p. 166-173 (2009).

[13] HUYNH (N.T.), ROGER (E.), LAUTRAM (N.), BENOIT (J.P.) et PASSIRANI (C.). - The rise and rise of stealth nanocarriers for cancer therapy : passive versus active targeting. $\mathrm{Na}$ nomedicine (Lond), 5, p. 1415-1433 (2010).

[14] WASHINGTON (N.), WASHINGTON (C.) et WILSON (C.G.) - Physiological pahrmaceutics. Barriers to drug absorption. second Edition : CRC Press (éd. 2001).

[15] DRESSMAN (J.B.), THELEN (K.) et JANTRATID (E.). - Towards Quantitative Prediction of Oral Drug Absorption. Clinical Pharmacokinetics, 47, p. 655-667 (2008).

[16] ROGER (E.), LAGARCE (F.), GARCION (E.) et BENOIT (J.P.) - Biopharmaceutical parameters to consider in order to alter the fate of nanocarriers after oral delivery. Nanomedicine (Lond), 5, p. 287-306 (2010).

[17] ROGER (E.), LAGARCE (F.) et BENOIT (J.P.). The gastrointestinal stability of lipid nanocapsules. Int J Pharm, 379, p. 260-265 (2009).

[18] MCCONNELL (E.L.), LIU (F.) et BASIT (A.W.). Colonic treatments and targets : issues and opportunities. J Drug Target, 17, p. 335-363 (2009).

[19] CRATER (J.S.) et CARRIER (R.L.). - Barrier properties of gastrointestinal mucus to nanoparticle transport. Macromol Biosci, 10, p. 1473-1483 (2010)

[20] ENSIGN (L.M.), CONE (R.) et HANES (J.). Oral drug delivery with polymeric nanoparticles : the gastrointestinal mucus barriers. Adv Drug Deliv Rev, 64, p. 557-570 (2012).

[21] GROO (A.C.), MIRCHEVA (K.), BEJAUD (J.), AILHAS (C.), PANAIOTOV (I.), SAULNIER (P.), IVANOVA (T.) et LAGARCE (F.). - Develop ment of 2D and 3D Mucus Models and Their Interactions with Mucus-Penetrating Paclitaxel-Loaded Lipid Nanocapsules. Pharm Res, (2014).

[22] GROO (A.C.) et LAGARCE (F.). - Mucus models to evaluate nanomedicines for diffusion. Drug Discov Today (2014).

[23] AMIDON (G.L.), LENNERN $\sqrt{ } \S S$ (H.), SHAH (V. P.) et CRISON (J.R.). - A theoritical basis for a biopharmaceutic Drug Classification. The correlation of in vitro Drug Product dissolu- tion an in vivo Bioavailability. Pharmaceutical Research, 12, p. 413-420 (1995).

[24] REIS (C.P.) et DAMGE (C.). - Nanotechnology as a promising strategy for alternative routes of insulin delivery. Methods Enzymol, 508, p. 271-294 (2012).

[25] RAMADAN (A.), LAGARCE (F.), TESSIERMARTEAU (A.), THOMAS (O.), LEGRAS (P.) MACCHI (L.), SAULNIER (P.) et BENOIT (J.P.). - Oral fondaparinux : use of lipid nanocapsules as nanocarriers and in vivo pharmacokinetic study. Int J Nanomedicine, 6, p. 29412951 (2011).

[26] ALVAREZ-ROMAN (R.), NAIK (A.), KALIA (Y N.), GUY (R.H.) et FESSI (H.). - Skin penetration and distribution of polymeric nanoparticles. J Control Release, 99, p. 53-62 (2004).

[27] GUPTA (M.), AGRAWAL (U.) et VYAS (S.P.). Nanocarrier-based topical drug delivery for the treatment of skin diseases. Expert Opin Drug Deliv, 9, p. 783-804 (2012).

[28] PROW (T.W.), GRICE (J.E.), LIN (L.L.), FAYE (R.), BUTLER (M.), BECKER (W.), WURM (E. M.), YOONG (C.), ROBERTSON (T.A.), SOYER (H.P.) et ROBERTS (M.S.). - Nanoparticles and microparticles for skin drug delivery. Adv Drug Deliv Rev, 63, p. 470-491 (2011).

[29] RESNIER (P.), MONTIER (T.), MATHIEU (V.), BENOIT (J.P.) et PASSIRANI (C.). - A review of the current status of siRNA nanomedicines in the treatment of cancer. Biomaterials, 34 , p. $6429-6443$ (2013)

[30] DAVID (S.), CARMOY (N.), RESNIER (P.), DENIS (C.), MISERY (L.), PITARD (B.), BENOIT (J.P.), PASSIRANI (C.) et MONTIER (T.). - In vivo imaging of DNA lipid nanocapsules after systemic administration in a melanoma mouse model. Int J Pharm, 423, p. 108-115 (2012).

[31] TODOROFF (J.) et VANBEVER (R.). - Fate of nanomedicines in the lung. Current opinion in colloid \& interface science, 16, p. 246-254 (2011).

[32] MANSOUR (H.M.), RHEE (Y.S.) et WU (X.). Nanomedicine in pulmonary delivery. Int $\mathrm{J}$ Nanomedicine, 4, p. 299-319 (2009).

[33] CRYAN (S.A.), SIVADAS (N.) et GARCIACONTRERAS (L.). - In vivo animal models for drug delivery across the lung mucosal barrier. Adv Drug Deliv Rev, 59, p. 1133-1151 (2007). 


\section{À lire également dans nos bases}

VAUTHIER (C.) et COUVREUR (P.) - Nanotechnologies pour la thérapeutique et le diagnostic. [NM 4 010].

BENOIT (J.P.) et RICHARD (J.). - Microencapsulation. [J 2 210].
GEORGE (S.) et LAMPROYE (N.). - Caractérisation des nano-objets. [K 70].

VIDIC (J.). - Nanoparticules pour les applications antibactériennes, antifongiques et antivirales. [NM 4 060].
DURAND (J.O) et RAEHM (L.) - Nonoparticules mésoporeuses de silice (MSN) et applications biologiques. [NM 4 050].

SILBERZAN (P.). - Apports des micro-nano technologies à l'étude de la mécanique celluaire. [NM 4 100].

\section{Sites Internet}

European technology platform on nanomedicine : ETP - Nanomedicine. http://www.etp-nanomedicine.eu/public 


\section{TECHNIQUES DE L'INGÉNIEUR UNE APPROCHE GLOBALE DE VOS BESOINS}

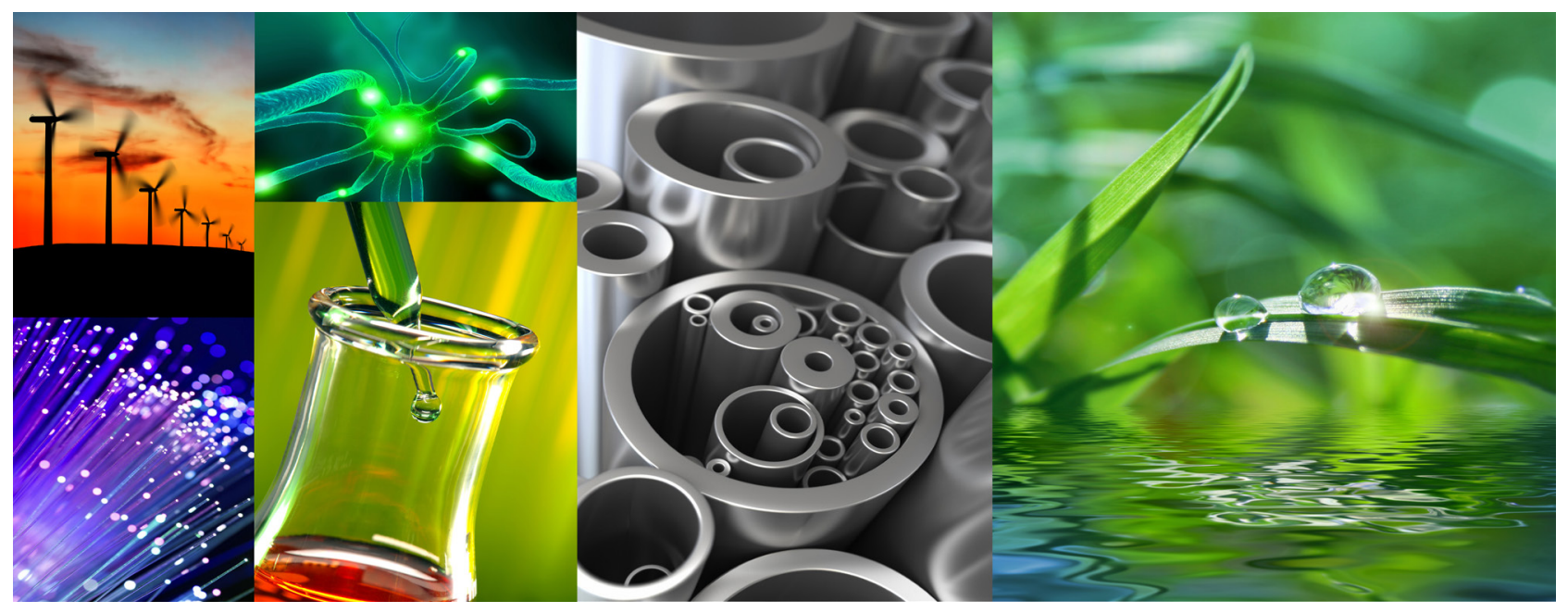

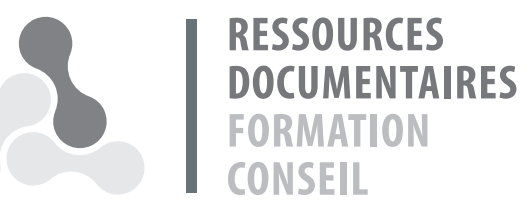

Plus de $\mathbf{8 0 0 0}$ articles scientifiques et techniques en français et les services associés pour aller plus loin dans vos recherches documentaires et bibliographiques.

Techniques de l'ingénieur est la base de référence des bureaux d'études et de la conception, de la R\&D, de la recherche et de l'innovation industrielle.

\section{RESSOURCES DOCUMENTAIRES FORMATION CONSEIL}

Les experts de Techniques de l'Ingénieur partagent leurs savoir-faire techniques et organisationnels.

Montez en compétence grâce aux journées techniques et formations HSE ou privilégiez un parcours sur mesure développé par les conseillers formation et réalisé à vos dates et dans votre établissement.

\section{RESSOURCES DOCUMENTAIRES FORMATION CONSEIL}

Tout l'ADN de Techniques de l'Ingénieur à votre disposition.

Les experts et spécialistes scientifiques de Techniques de l'Ingénieur, praticiens expérimentés, vous accompagnent tout au long de vos projets pour vous conseiller : diagnostics, recommandations techniques et montée en capacité de votre R\&D jusqu'à l'innovation.

\section{LES THÉMATIQUES COUVERTES}

Sciences fondamentales

Génie industriel

Procédés Chimie-Agro-Bio

Mesures - Analyse

Matériaux

Mécanique

Énergies
Électronique - Automatique

Technologies de l'information

Construction

Innovations

Environnement - Sécurité

Transports

Biomédical - Pharma 
Accédez à l'information la plus pertinente, approuvée par plus de 300000 utilisateurs parmi vos clients, fournisseurs ou partenaires, grâce à votre abonnement aux ressources documentaires et services inclus ${ }^{(1)}$ :

SÉMINAIRES EN LIGNE : profitez, tout au long de l'année, de formations à distance sur le thème : " Optimiser sa veille scientifique et technologique avec Techniques de l'Ingénieur ». Ces séminaires vous montrent comment exploiter au mieux les ressources et fonctionnalités de techniques-ingenieur.fr et améliorer la pertinence de vos résultats de recherche.

\section{SERVICE OUESTIONS-RÉPONSES}

Besoin de compléments d'information ou de validation pour mieux prendre vos décisions ? Posez des questions techniques, scientifiques, réglementaires, juridiques ou encore économiques aux plus grands spécialistes des domaines couverts par vos bases documentaires, c'est compris dans votre abonnement !

\section{DICTIONNAIRE TECHNIOUE}

MULTILINGUE : cet outil en ligne propose plus de 45000 termes scientifiques et techniques relatifs aux domaines qui vous concernent. Pour 10000 d'entre eux, retrouvez des illustrations, avec légendes, elles aussi toujours traduites en 4 langues.

\section{ARTICLES DÉCOUVERTE : bénéficiez}

d'un crédit de 1 à 5 articles au choix, à consulter gratuitement, dans les bases documentaires auxquelles vous n'êtes pas abonné.

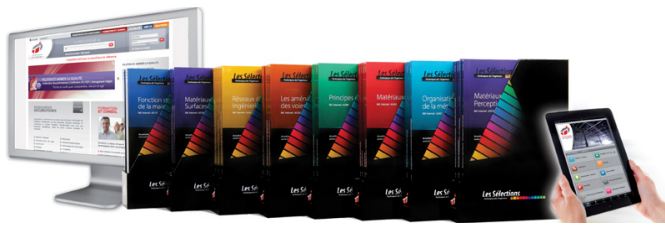

COMPLEMENT 360 : en complément des ressources documentaires comprises dans votre abonnement, utilisez cet outil pour approfondir vos recherches en découvrant les autres publications également disponibles sur internet.Vous accédez à toutes les références bibliographiques liées au sujet qui vous concerne

\section{ANNUATRF DFS T,ABORATOIRES FT}

CENTRES DE RECHERCHE : pour chacune des bases documentaires, vous avez à disposition une sélection pertinente des 15 premiers centres de recherche, profils de chercheur, projets et publications parmi les données de plus de 50000 centres de recherche privés et publics.

ARCHIVES : accédez aux versions antérieures de vos articles, ainsi qu'à ceux qui traitent des technologies plus anciennes.

\section{SERVICE ACTUALITÉ : pour une vision globale et} quotidienne de l'actualité et des innovations technologiques, Techniques de l'Ingénieur met à votre disposition un service de Veille \& Actualités. Ce service regroupe en 11 thématiques les grands domaines de l'ingénierie pour donner au lecteur une visibilité globale des dernières innovations.

MOBILIT'É : Techniques de l'Ingénieur propose un site internet intégralement compatible mobile et tablettes (iPad).

ET AUSSI : le statut d'abonné vous donne accès à des prestations complémentaires, sur devis : l'impression à la demande pour obtenir un ou plusieurs ouvrages supplémentaires (versions imprimées de vos bases documentaires) ou encore la traduction d'un article dans la langue de votre choix.

\section{En savoir plus ou découvrir le contenu de Techniques de l'Ingénieur?}

\section{Les conseillers régionaux de Techniques de l'Ingénieur sont à votre écoute pour vous proposer des solutions sur mesure.}

Pour recevoir, sans engagement de votre part, toute l'information sur les produits des Techniques de I'Ingénieur, complétez cette demande d'information.

A retourner à :
Techniques de l'Ingénieur
249 rue de Crimée
75925 Paris cedex 19
Tél. : 0153352020
Fax:0153267918
email : infos.clients@teching.com
de I'Ingénieur
$\square \mathrm{M} . \square \mathrm{Mme}$
Nom :..............................Prénom :

Société/Organisme

Adresse

CP: $L \perp\left|\_\right| \_\mid$Ville

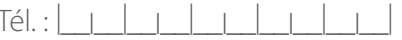

Fax :

Email

Effectif :

NAF : 